\title{
使用归结和调解的输入反驳与 单元反驳不等价 ${ }^{*}$
}

孙吉贵刘华

(吉林大学计筆机科学系, 长春 130023)

\section{关掼诃调解、对称调解、单元反驱、输入反驱}

Chang 和 Lee 在文献[1]中给出了如下结果:

定理 8.4 如果子句集 $S$ 有使用归结和调解的输入反玫, 则 $S$ 与函数自反公理集的并 集有使用归结和调解的单元反玫。

它理 8.5 设 $S$ 是 $E$-不可满足的单元子句集, 其中包含 $x=x$ 和函数自反公理集, 若 $C$ 是 $S$ 中子句, 且 $S-\{C\}$ 是 $E$-可满足的, 则 $S$ 有使用归结和调解以子句 $C$ 为顶的输人反 牧.

它理 8.6 设 $S$ 是 $E$-不可满足的子句集, 其中包含 $x=x$ 和函数自反公理集, 若 $C$ 是 $S$ 中子句, 且 $S-\{C\}$ 是 $E$-可满足的, 则 $S$ 有使用归结和调解以子句 $C$ 为顶的线性反驭, 并 推测定理 8.4 的逆也是对的, 但未得到证明 (参见文献 [1]第 175 页). 而此推测与定理 8.4 的 结合就是下面的结论: 对于包含 $x=\boldsymbol{x}$ 和函数自反公理集的子句集, 使用归结和调解的输人 反驳与单元反驳等价. 本文通过反例指出上述推测是不正确的; 定理 8.5 和定理 8.6 也有问 题.

定义 1 w 设 $C_{1} 、 C_{2}$ 是两个没有公共变量的子句(称为调解子句), $C_{1}$ 为 $L[t] \vee C_{1}^{\prime}, C_{2}$ 为 $r-s \vee C_{2}^{\prime}$, 其中 $L[t]$ 为含有项 $t$ 的文字, $C_{1}^{\prime} 、 C_{2}^{\prime}$ 为子句. 如果 $t$ 和 $r$ 有最一般合一 $\mathrm{mgu} \sigma$, 则称

$$
L^{\sigma}\left[S^{\sigma}\right] \cup C_{1}^{\prime \sigma} \cup C_{2}^{\prime \sigma}
$$

为 $C_{1} 、 C_{2}$ 的二元调解式. 其中, $L^{\circ}\left[S^{\infty}\right]$ 表示用 $S^{\sigma}$ 替代 $L^{\circ}$ 中 的某次出现. 文字 $L$ 和 $r=S$ 称为调解文字. 一没称上述过程为 $C_{2}$ 到 $C_{1}$ 使用调解.

定义 2 设 $C_{1} 、 C_{2}$ 是两个没有公共变量的子句(称为对称调解子句), $C_{1}$ 为 $L[t] \vee C_{1}^{\prime}$, $C_{2}$ 为 $r-S \vee C_{2}^{\prime}$, 其中 $L[z]$ 为含有项 $t$ 的文字, $C_{1}^{\prime} 、 C_{2}^{\prime}$ 为子句. 如果 $t$ 和 $r$ 有最一般合一 $\mathrm{mgu} \sigma$, 或者 $t$ 与 $S$ 有最一般合一 $\mathrm{mgu} \tau$, 则称

$$
L^{\sigma}\left[s^{\sigma}\right] \cup C_{1}^{\prime \sigma} \cup C_{2}^{\prime \sigma}, L^{\mathrm{r}}\left[r^{\tau}\right] \cup C_{1}^{\prime r} \cup C_{2}^{\prime \tau}
$$

为 $C_{1} 、 C_{2}$ 的二元对称调解式.

命且 $1 S$ 为一般子句集, $S$ 有使用归结和调解的单元反玫, 但 $S$ 末必有使用归结和调 解的输人反玫. 从而, 使用归结和调解的输人反驭与单元反驭不等价.

本文 1990 年 10 月 29 日收到. 1991 年 8 月 3 日收到悠改䊈.

- 国家自然科学基金资助项目. 
例 1 设 $S$ 为 $\left\{L\left(S_{1}\right) \vee L\left(S_{2}\right), \sim L\left(S_{1}\right) \vee \sim L\left(S_{3}\right), S_{3}-S_{1}, S_{2}-S_{1}, S_{1}-S_{1}, S_{2}-S_{2}\right.$, $\left.S_{3}-S_{3}\right\}$, 则 $S$ 有使用归结和调解的单元反驳如下图:

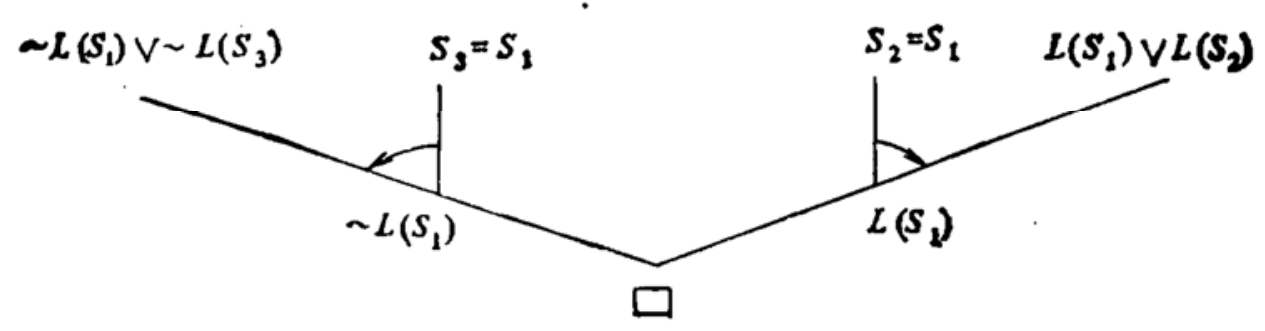

但 $S$ 没有使用归结和调解的输人反驳. 事实上, 因为输人反驳演绎的最后一步必然是两个互 补单文字子句的归结, 注意到 $S$ 中的单文字子句只有等词, 而 $S$ 的任何使用归结和调解的演绎 都不会演绎出不等词, 故 $S$ 没有使用归结和调解的输人反玫.

因此, Chang 和 $\mathrm{Lee}^{\mathrm{d}}$ 的推测是错误的.

从例 1 中还可以看出,即使允许使用对称调解, 命题 1 仍然是对的.

命愿 2 在调解的定义下,文献 [1]中的引理 8.2、引理 8.3、定理 8.5、引理 8.4 和定理 8.6 都是错误的. 从而, 即使对于单元句集, 使用归结和调解的输人反牧与单元反教也不等 价.

对于一般子句集, 使用归结和调解的线性反驳不完备.

我们看下面的例子:

例 2 设 $L^{\prime}$ 为 $L(a), M^{\prime}$ 为 $b-b^{\prime}, S_{1}-S_{2}$ 为 $b=a, L$ 为 $L(b), M$ 为 $a-b$, 则 如下的演绎与引理 8.2 的图 $8.3 \mathrm{a}^{\text {(2) }}$ 是一样的:

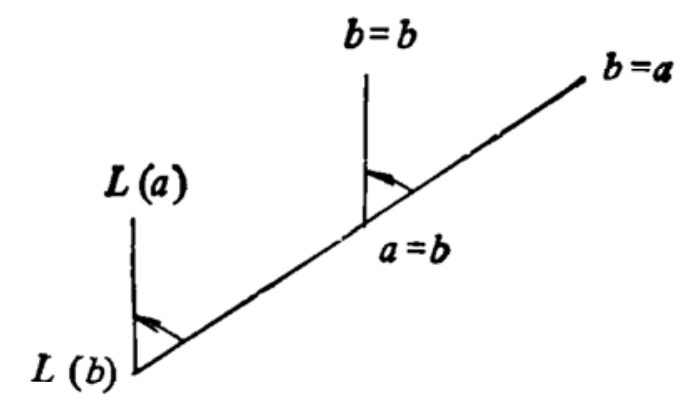

但是, 若调解不具有对称性, 则 $L(a)$ 与 $b-b, b-a$ 既不能作归结也不能作调解, 从而上 述演绎不能转化为图 8.3b 或图 8.3c 所示的演绎. 因此,引理 8.2 是不正确的.

例 3 设 $S$ 为 $\left\{L\left(a_{1}, a_{2}\right), \sim L\left(b_{1}, b_{2}\right), a_{1}-c_{1}, b_{1}-c_{1}, a_{2}-c_{2}, b_{2}-c_{2}, a_{1}-a_{1}, b_{1}=b_{1}\right.$, $\left.c_{1}-c_{1}, a_{2}-a_{2}, b_{2}-b_{2}, c_{2}-c_{2}\right\}$, 则 $S$ 是 $E$-不可满足的基单元子句集, 且其中包含 $x=$ $x$ 的所有基例. $S-\left\{L\left(a_{1}, a_{2}\right)\right\}$ 是 $E$-可满足的. $S$ 有使用归结和调解的单元反牧 如 下 图: 


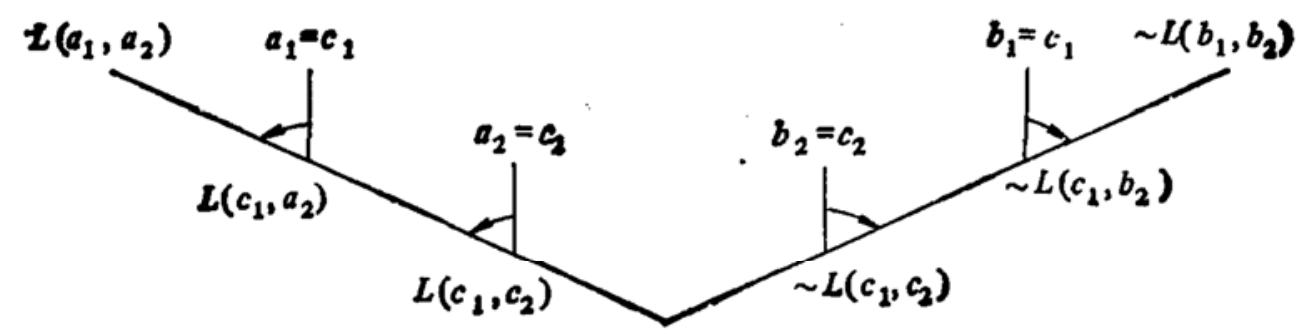

但是, 若调解不具有对称性,则 $S$ 没有使用归结和调解以 $L\left(a_{1}, a_{2}\right)$ 为顶子句的输人反玫.

事实上, $S$ 中没有能与 $L\left(a_{1}, a_{2}\right)$ 作归结的子句, 能与 $L\left(a_{1}, a_{2}\right)$ 作调解的子句只有 $a_{1}=$ $c_{1}, a_{2}-c_{2}, a_{1}-a_{1}, a_{2}-a_{2}$. 而后两个子句与 $L\left(a_{1}, a_{2}\right)$ 的调解式仍为 $L\left(a_{1}, a_{2}\right)$, 所以只能用 $a_{1}-c_{1}, a_{2}-c_{2}$ 与 $L\left(a_{1}, a_{2}\right)$ 作调解. 不妨用 $a_{1}-c_{1}$ 与 $L\left(a_{1}, a_{2}\right)$ 作调解, 得调解式 $L\left(c_{1}\right.$, $\left.a_{2}\right)$; 同样 $S$ 中没有子句能与 $L\left(c_{1}, a_{2}\right)$ 作归结, 能与 $L\left(c_{1}, a_{2}\right)$ 作调解的子句只有 $c_{1}=c_{1}$, $a_{2}-a_{2}, a_{2}-c_{2}$. 前两者与 $L\left(c_{1}, a_{2}\right)$ 的调解式仍为 $L\left(c_{1}, a_{2}\right)$, 所以只能用 $a_{2}-c_{2}$ 与 $L\left(c_{1}\right.$, $\left.a_{2}\right)$ 作调解, 得调解式 $L\left(c_{1}, c_{2}\right)$; 显然 $S$ 中没有子句能与 $L\left(c_{1}, c_{2}\right)$ 作归结, 能与 $L\left(c_{1}, c_{2}\right)$ 作 调解的子句只有 $c_{1}-c_{1}, c_{2}-c_{2}$, 而两者与 $L\left(c_{1}, c_{2}\right)$ 的调解式仍为 $L\left(c_{1}, c_{2}\right)$, 故演绎无法再 进行下去. 因此, $S$ 没有使用归结和调解以子句 $L\left(a_{1}, a_{2}\right)$ 为顶的输人反驳. 于是, 引理 8.3 和定理 8.5 都是不正确的.

可以验证, $s$ 也没有使用归结和调解以其它子句为顶的输人反驳. 因此, 即使对于单元子 句集,使用归结和调解的输入反驳与单元反玫也不等价.

同样可以验证, $S$ 没有使用归结和调解以 $L\left(a_{1}, a_{2}\right)$ 或者其它子句为顶的线性反玫. 因 此,引理 8.4 和定理 $8.6^{\text {[d }}$ 是不正确的.

文献 [1]中对引理 8.2, 引理 8.3, 定理 8.5, 引理 8.4 和定理 8.6 的证明, 实际上使用了对称 调解. 因此,定理 8.5 和定理 $8.6 \mathrm{~W}$ 只需将调解改为对称调解, 就没有任何问题了.

结论 本文的对称调解, 不是对文献 [1]中调解概念的改进. 从机器证明的观点看, 调 解比对称调解要好. 但是,在 Chang 和 Lee 的调解概念下,线性调解是不完备的; 输入调解 甚至对 Horn 集都不完备. 如果使用对称调解, 则线性对称调解是完备的、输人对称调解和 单元对称调解在 Horn 集上都是完备的".

应该注意到,在 Chang 和 Lee 的调解概念下,调解和归结的结合是完备的. 例如, 文献 [1]中提出的 $P$-超调解和 $P$-超归结的结合是完备的. 因此, 调解和对称调解两个概念都是 需要的.

\section{今 站 献}

[1] Chang, C.L. and Lee, R.C.T.,Symbolic Logic and Mechanical Theorem Proving, Academic Press, New York, 1973.

[2]刘叙华、巻云て, 定理机器证明,科学出版社, 1987.

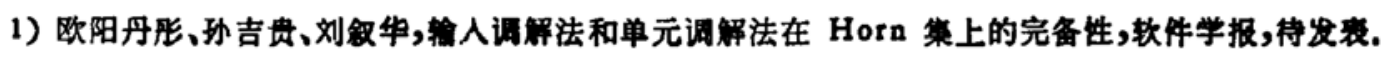

